\title{
Effective doses of cisatracurium in the adult and the elderly
}

\author{
Jeong Ho Kim, Yoon Chan Lee, Soo Il Lee, Sang Yoong Park, So Ron Choi, \\ Jong Hwan Lee, Chan Jong Chung, and Seung Cheol Lee
}

Department of Anesthesiology and Pain Medicine, Dong-A University Hospital, Busan, Korea

Background: There are few information about the differences of the effective dose (ED) of cisatracurium between the adult and the elderly. We investigated the ED and the onset time of cisatracurium in the adults and the elderly.

Methods: We studied two hundred patients of the adults aged 20 through 64 years and the elderly aged $\geq 65$ years, with American Society of Anesthesiologists physical status I or II. Each 100 patients with 20 patients of each dose group, randomly selected from $30,40,50,60$ or $70 \mu \mathrm{g} / \mathrm{kg}$ of cisatracurium, were randomly allocated to the adults and the elderly groups. We recorded the $0.1 \mathrm{~Hz}$ single twitch responses of the adductor pollicis and the onset times to maximal blockade. The magnitude of muscle relaxation was recorded by using an acceleromyography. The effect of cisatracurium on single twitch was calculated as percent reduction. After converting each drug dose into logarithm and percent reduction of the muscle reduction into probit, the EDs representing the muscle relaxation effects of 5\%, 25\%, 50\%, 75\% and 95\% were estimated using the linear regression analysis.

Results: No significant differences were found in age, weight, height, or body mass index within or between the groups. The $\mathrm{ED}_{50}$ and $\mathrm{ED}_{95}$ of the adult group were 35.39 and $59.58 \mu \mathrm{g} / \mathrm{kg}$. The $\mathrm{ED}_{50}$ and $\mathrm{ED}_{95}$ of the elderly group were 34.89 and $55.50 \mu \mathrm{g} / \mathrm{kg}$, respectively. The onset times were $375.4 \pm 76.9$ seconds in the adult group and $369.1 \pm 70.0$ seconds in the elderly group.

Conclusions: The ED and the onset time were not significantly different between the adult and the elderly.

Key Words: Aged, Cisatracurium.

\section{Introduction}

Cisatracurium, a stereoisomer of atracurium, is a non-depolarizing, benzylisoquinolinium intermediate-acting, neuromuscular blocking agent with 4 times the potency of atracurium.

Corresponding author: Seung Cheol Lee, M.D., Ph.D.

Department of Anesthesiology and Pain Medicine, Dong-A University

Hospital, 26, Daesingongwon-ro, Seo-gu, Busan 49201, Korea

Tel: 82-51-240-5390, Fax: 82-51-247-7819

E-mail: k57501@dau.ac.kr

ORCID: http://orcid.org/0000-0001-8669-5517

Received: February 1, 2016.

Revised: May 25, 2016 (1st); June 16, 2016 (2nd).

Accepted: June 23, 2016.

Korean J Anesthesiol 2016 October 69(5): 453-459

http://dx.doi.org/10.4097/kjae.2016.69.5.453
Cisatracurium decomposes into laudanosin and a tetravalent alcohol metabolite by Hofmann elimination in the blood plasma and extracellular fluid; hence, the recovery of muscle relaxation is hardly affected by diseases of the liver and kidney [1]. Due to these characteristics, cisatracurium has been used widely in managing intensive care unit patients, as well as in general anesthesia.

According to September 2013 data from Statistics Korea, the proportion of elderly people aged $\geq 65$ years was $12.2 \%$, a great increase compared with $3.1 \%$ in 1970 ; moreover, the rate is expected to further increase to $37.4 \%$ in 2050 [2]; accordingly, surgeries for the elderly that require general anesthesia are also expected to increase in number. Because of age-related changes in how the body processes medications, elderly patients are more sensitive to anesthetics, exhibiting side effects even with ordinary doses. In addition, the drug effects in this population are often prolonged $[3,4]$. Although a number of studies have

(c) This is an open-access article distributed under the terms of the Creative Commons Attribution Non-Commercial License (http://creativecommons.org/ licenses/by-nc/4.0/), which permits unrestricted non-commercial use, distribution, and reproduction in any medium, provided the original work is properly cited. 
compared the effects of muscle relaxants in the elderly, few have focused on the effective dose (ED) of cisatracurium and changes in the ED with aging in Koreans. We thus investigated the ED and onset time of cisatracurium for Korean adults aged 20 through 64 years and elderly Koreans aged $\geq 65$ years.

\section{Materials and Methods}

The study was approved by the Clinical Ethics Committee, and informed consent was obtained from all patients before surgery. Among patients who were awaiting surgery after intubation under general anesthesia, adults were selected who were aged 20 through 64 years or aged $\geq 65$ years and who had American Society of Anesthesiologists physical classifications 1 and 2, had no history of liver disease, renal disease, parathyroid disease, or hypercalcemia, and who had body mass indexes (BMI) of 18.5 to 24.9. Patients were excluded as test subjects if they were expected to bleed excessively, were scheduled for major surgery that would require massive hydration, were taking drugs (magnesium sulfate, lithium, antiepileptic drug) that would interact with non-depolarizing neuromuscular blocking agents, or would show adverse effects with the drug used in this study.

All patients received the following premedication after fasting since midnight: diazepam $5.0 \mathrm{mg}$ orally, glycopyrrolate $0.2 \mathrm{mg}$ and butorphanol $1.0 \mathrm{mg}$ injected intramuscularly, and ranitidine $50 \mathrm{mg}$ injected intravenously. Monitoring used the standard noninvasive method: attaching standard electrocardiograph electrodes II, a blood pressure measurement device, pulse oxygen saturation instrumentation and an end-tidal carbon dioxide concentration measurement device for all patients as they entered the operating room.

After anesthesia was induced with an intravenous injection of $2 \mathrm{mg} / \mathrm{kg}$ propofol (Propofol ${ }^{\circledR}$, Dongkook Pharmaceutical Co.,

Table 1. Demographic Data

A.

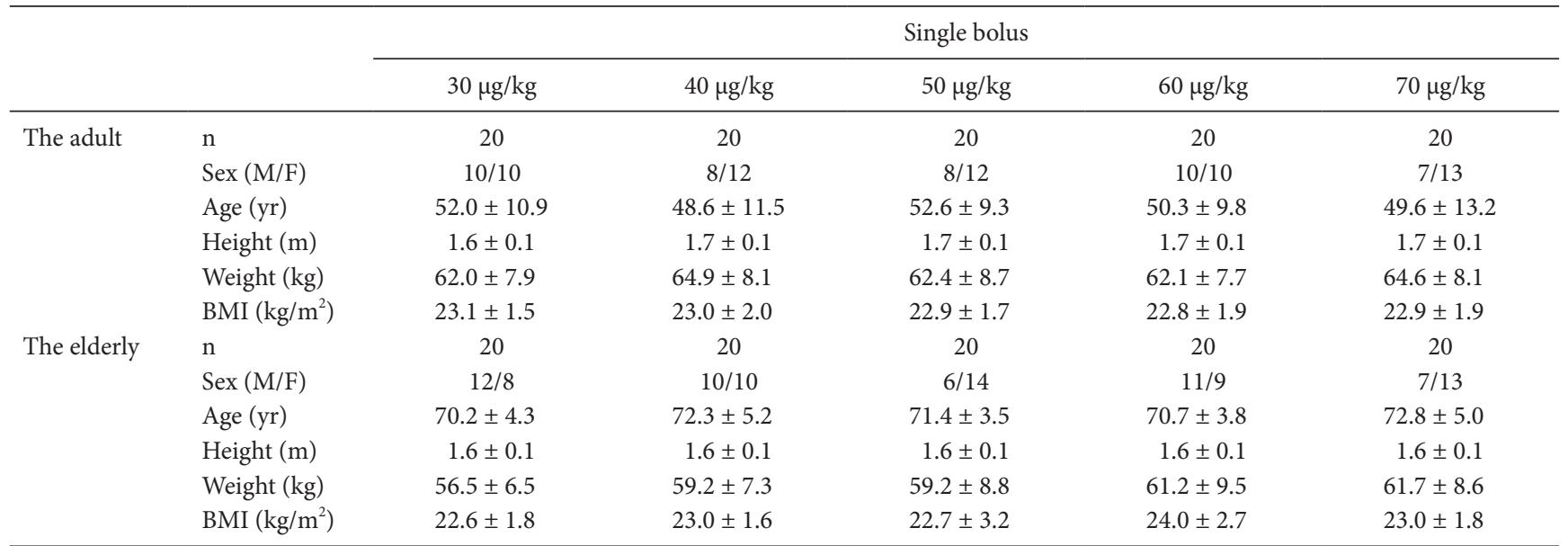

Values are mean \pm SD. n: number of patients, BMI: body mass index. The adult: $<65$ years old. The elderly: $\geq 65$ years old. There were no significant differences between two groups except for age.

B.

\begin{tabular}{|c|c|c|c|c|c|c|}
\hline & & \multicolumn{5}{|c|}{ Single bolus } \\
\hline & & $30 \mu \mathrm{g} / \mathrm{kg}$ & $40 \mu \mathrm{g} / \mathrm{kg}$ & $50 \mu \mathrm{g} / \mathrm{kg}$ & $60 \mu \mathrm{g} / \mathrm{kg}$ & $70 \mu \mathrm{g} / \mathrm{kg}$ \\
\hline \multirow[t]{5}{*}{ Male } & $\mathrm{n}$ & 22 & 18 & 14 & 21 & 14 \\
\hline & Age (yr) & $63.7 \pm 10.9$ & $62.6 \pm 13.8$ & $59.3 \pm 12.7$ & $61.1 \pm 13.0$ & $61.1 \pm 16.7$ \\
\hline & Height (m) & $1.6 \pm 0.1$ & $1.6 \pm 0.1$ & $1.6 \pm 0.0$ & $1.6 \pm 0.1$ & $1.6 \pm 0.1$ \\
\hline & Weight (kg) & $55.3 \pm 4.9$ & $56.7 \pm 5.7$ & $55.0 \pm 5.1$ & $57.4 \pm 8.1$ & $56.3 \pm 8.6$ \\
\hline & BMI $\left(\mathrm{kg} / \mathrm{m}^{2}\right)$ & $23.0 \pm 1.6$ & $22.7 \pm 1.8$ & $22.2 \pm 1.8$ & $23.5 \pm 2.5$ & $22.6 \pm 2.1$ \\
\hline \multirow[t]{5}{*}{ Female } & $\mathrm{n}$ & 18 & 22 & 26 & 19 & 26 \\
\hline & Age (yr) & $57.9 \pm 13.5$ & $58.6 \pm 15.9$ & $63.5 \pm 11.2$ & $59.7 \pm 12.7$ & $61.2 \pm 14.9$ \\
\hline & Height (m) & $1.7 \pm 0.1$ & $1.7 \pm 0.1$ & $1.7 \pm 0.1$ & $1.7 \pm 0.1$ & $1.7 \pm 0.1$ \\
\hline & Weight (kg) & $64.1 \pm 7.7$ & $66.5 \pm 7.2$ & $64.0 \pm 8.8$ & $66.4 \pm 6.5$ & $66.8 \pm 5.5$ \\
\hline & BMI $\left(\mathrm{kg} / \mathrm{m}^{2}\right)$ & $22.8 \pm 1.8$ & $23.2 \pm 1.8$ & $23.1 \pm 2.8$ & $23.3 \pm 2.3$ & $23.1 \pm 1.7$ \\
\hline
\end{tabular}

Values are mean \pm SD. n: number of patients, BMI: body mass index. There were no significant differences between two groups except for age. 
Seoul, Korea), it was maintained with an IV infusion of $5 \mathrm{mg} / \mathrm{kg} /$ $h$, and the depth of the anesthesia was confirmed by bispectral index. Oxygen was supplied through facial masks using 100\% oxygen in a manual respirator, and end-tidal carbon dioxide concentration was maintained at $30-37 \mathrm{mmHg}$.

To assess muscle relaxation, the magnitude of relaxation (\% control) was recorded using an acceleromyograph (TOFGuard ${ }^{\circledR}$, Organon Teknika BV, Boxtel, Netherlands) as a peripheral nerve stimulator. The electrode was attached at a 7-11 $\mathrm{mm}$ range and 3-6 cm interval on the ulnar nerve travel site in the forearm on the opposite side from the blood pressure measurement device; each patient's deep body temperature was maintained at more than $35^{\circ} \mathrm{C}$, and peripheral skin temperature was maintained at more than $32^{\circ} \mathrm{C}$. Before muscle relaxants were administered, $50 \mathrm{~Hz}$ supramaximal tetanic stimulation was conducted for 5 seconds, and the response was stabilized with a $0.1 \mathrm{~Hz}$ singletwitch stimulus for 5 minutes; subsequently, thumb adductor spasmodic response was recorded with a $0.1 \mathrm{~Hz}$ the singleswitch stimulus; after the stabilization, we selected $100 \%$ for the size of the single twitch. The effect of cisatracurium on a single twitch was calculated as percent reduction (= 100 - spasm size in percent).

A dose-response study on cisatracurium $\left(\right.$ Nimbex ${ }^{\circledR}$, GlaxoSmithKline plc., Brentford, Middlesex, England) was conducted by measuring and recording the maximum muscle relaxation effect (\% control) of the single twitch, as well as the time taken for the effect to reach the maximum after a randomly selected dose (from 30, 40, 50, 60 and $70 \mu \mathrm{g} / \mathrm{kg}$ ) was administered within 5 seconds using a single bolus in 20 patients per dose in both adult

Table 2. Reduction of Single Twitch at Each Dose Group

\begin{tabular}{ccc}
\hline \multirow{2}{*}{ Single bolus } & \multicolumn{2}{c}{ Maximum muscle relaxation effect (\% control) } \\
\cline { 2 - 3 } & The adult & The elderly \\
\hline $30 \mu \mathrm{g} / \mathrm{kg}$ & $35.7 \pm 7.1$ & $39.1 \pm 9.1$ \\
$40 \mu \mathrm{g} / \mathrm{kg}$ & $55.5 \pm 7.0$ & $57.6 \pm 6.2$ \\
$50 \mu \mathrm{g} / \mathrm{kg}$ & $82.6 \pm 6.2$ & $83.6 \pm 5.2$ \\
$60 \mu \mathrm{g} / \mathrm{kg}$ & $91.6 \pm 5.2$ & $93.5 \pm 4.4$ \\
$70 \mu \mathrm{g} / \mathrm{kg}$ & $94.4 \pm 4.2$ & $95.6 \pm 3.3$ \\
\hline
\end{tabular}

Values are mean \pm SD. The adult: $<65$ years old. The elderly: $\geq 65$ years old. There were no significant differences between two groups. and elderly patient groups. The relaxation effect and onset time were continuously monitored; the maximum relaxation effect was defined as the maximum calculated result, and the onset time was determined as the time to attain the maximum calculated result after confirmation that the relaxation had reached its maximum and had begun to decrease. After the study was complete, additional doses of cisatracurium were administered up to a total dose of $150 \mu \mathrm{g} / \mathrm{kg}$, and intubation was performed after confirmation that the muscle relaxation had reached the maximum.

After each drug dose had been converted into a logarithm and percent reduction of the muscle relaxation into a probit, we estimated the effective doses for muscle relaxation effects of $5 \%$, $25 \%, 50 \%, 75 \%$ and $95 \%$ using linear regression analysis. In the current study, we compared the ED values obtained by linear regression in which the reliability increased with the number of subjects, and the results for all 200 subjects, the 100 adult subjects and the 100 elderly subjects were all statistically significant. Age, height, weight, BMI and onset time were compared between the patient groups using ANOVA, with $\mathrm{P}$ value of < 0.05 considered statistically significant. All measurements are expressed as mean \pm SD or $95 \%$ confidence interval.

\section{Results}

No statistically significant differences were observed in height, weight or BMI either within or between groups (Table 1A). Additionally, no statistically significant difference was observed in the maximum muscle relaxation effect by dose between the two groups (Table 2).

The estimated $\mathrm{ED}_{50}$ and $\mathrm{ED}_{95}$ for the total patient group were $35.11(95 \%$ CI 32.65, 37.16) and $57.31 \mu \mathrm{g} / \mathrm{kg}$ (95\% CI 54.40, 60.19), respectively. The $\mathrm{ED}_{50}$ and $\mathrm{ED}_{95}$ for the adult group were 35.39 (95\% CI 31.76, 38.29) and $59.58 \mu \mathrm{g} / \mathrm{kg}$ (95\% CI 55.46, 65.14), respectively, and the $\mathrm{ED}_{50}$ and $\mathrm{ED}_{95}$ for the elderly group were 34.89 (95\% CI 31.28, 37.79) and $55.50 \mu \mathrm{g} / \mathrm{kg}(95 \% \mathrm{CI}$ $51.90,59.50$ ), respectively (Table 3 ). There was no significant difference in $\mathrm{ED}_{50}$ or $\mathrm{ED}_{95}$ between the two groups.

The average onset time for the maximum muscle relaxation to appear was $375.4 \pm 76.9$ seconds in the adult group and 369.1 \pm 70.0 seconds in the elderly group; no statistical difference was

Table 3. Effective Dose of Cisatracurium

\begin{tabular}{lccccc}
\hline & \multicolumn{5}{c}{ Effective dose $(\mu \mathrm{g} / \mathrm{kg})$} \\
\cline { 2 - 6 } & $\mathrm{ED}_{5}$ & $\mathrm{ED}_{25}$ & $\mathrm{ED}_{50}$ & $\mathrm{ED}_{75}$ & $\mathrm{ED}_{95}$ \\
\hline Total & $21.42(18.50,23.95)$ & $28.72(25.91,30.99)$ & $35.11(32.65,37.16)$ & $42.92(40.79,44.87)$ & $57.31(54.40,60.19)$ \\
The adult & $21.03(16.51,24.55)$ & $28.59(24.44,31.81)$ & $35.39(31.76,38.29)$ & $43.82(40.75,46.68)$ & $59.58(55.46,65.14)$ \\
The elderly & $21.85(17.40,25.37)$ & $28.84(24.74,32.00)$ & $34.89(31.28,37.79)$ & $42.20(39.09,44.97)$ & $55.50(51.90,59.50)$ \\
\hline
\end{tabular}

Values are mean (95\% confidence interval). The adult: $<65$ years old. The elderly: $\geq 65$ years old. 
observed by age or administer dose (Table 4). Additionally, the slope of the dose-response regression line for cisatracurium did not deviate from parallel in either the adult or the elderly groups (Fig. 1).

In addition, we compared the subjects by gender (Table 1B), and the mean maximum muscle relaxation by dose showed no significant gender difference (Fig. 2). However, a significant difference was observed in the $\mathrm{ED}_{95}$ by gender; the $\mathrm{ED}_{50}$ and $\mathrm{ED}_{95}$ for men were 35.79 (95\% CI 33.34, 37.89) and $64.50 \mu \mathrm{g} / \mathrm{kg}(95 \%$ CI $61.07,68.41)$, respectively, whereas the same two values for women were 34.47 (95\% CI 30.74, 37.46) and $51.13 \mu \mathrm{g} / \mathrm{kg}(95 \%$ CI $47.63,54.85)$, respectively.

\section{Discussion}

The proper use of neuromuscular blocking agents during surgery is necessary for surgical conditions. However, because

Table 4. Onset Time of Maximal Effect of Cisatracurium at Each Dose Group

\begin{tabular}{lcc}
\hline \multirow{2}{*}{ Single bolus } & \multicolumn{2}{c}{ Onset time (second) } \\
\cline { 2 - 3 } & The adult & The elderly \\
\hline Total & $375.4 \pm 76.9$ & $369.1 \pm 70.0$ \\
$30 \mu \mathrm{g} / \mathrm{kg}$ & $356.5 \pm 67.4$ & $352.0 \pm 57.6$ \\
$40 \mu \mathrm{g} / \mathrm{kg}$ & $363.1 \pm 54.1$ & $346.5 \pm 56.6$ \\
$50 \mu \mathrm{k} / \mathrm{kg}$ & $367.0 \pm 81.4$ & $370.0 \pm 81.1$ \\
$60 \mu \mathrm{kg}$ & $393.5 \pm 88.4$ & $383.5 \pm 78.9$ \\
$70 \mu \mathrm{g} / \mathrm{kg}$ & $397.0 \pm 86.2$ & $393.5 \pm 67.1$ \\
\hline
\end{tabular}

Values are mean \pm SD. The adult: $<65$ years old. The elderly: $\geq 65$ years old. There were no significant differences between two groups.

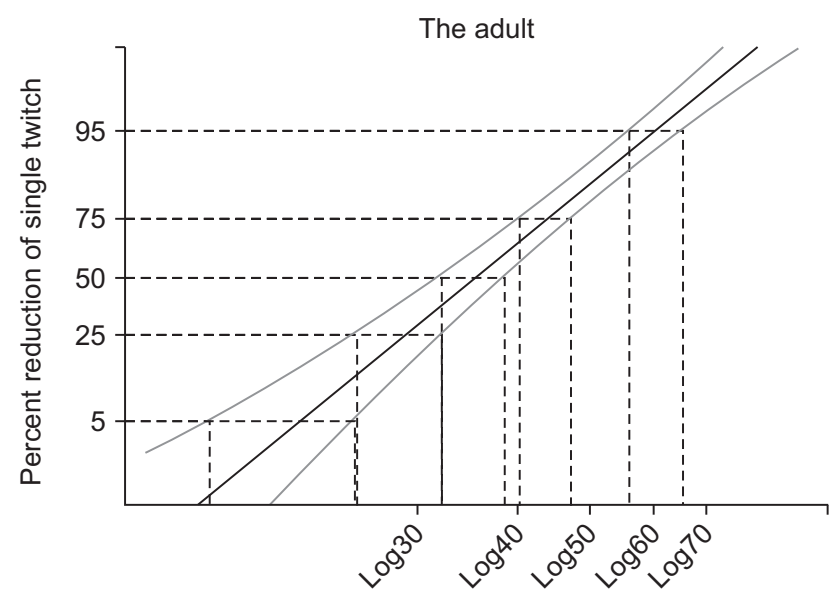

Log dose of cisatracurium $(\mu \mathrm{g} / \mathrm{kg})$ incomplete recovery of muscle relaxation risks hypoxia, pulmonary complications, aspiration or airway obstruction, appropriate doses of these agents are very important. In a study by Maybauer et al. [5], the rates of residual paralysis following administration of cisatracurium and rocuronium were $57 \%$ and $44 \%$, respectively.

Cisatracurium, a non-depolarizing, benzylisoquinolinium intermediate-acting, neuromuscular agent, decomposes into laudanosin and a tetravalent alcohol metabolite by Hofmann elimination. Because this decomposition occurs in the blood plasma and extracellular fluid, the recovery of muscle relaxation is little affected by liver or kidney diseases. Twenty-three percent

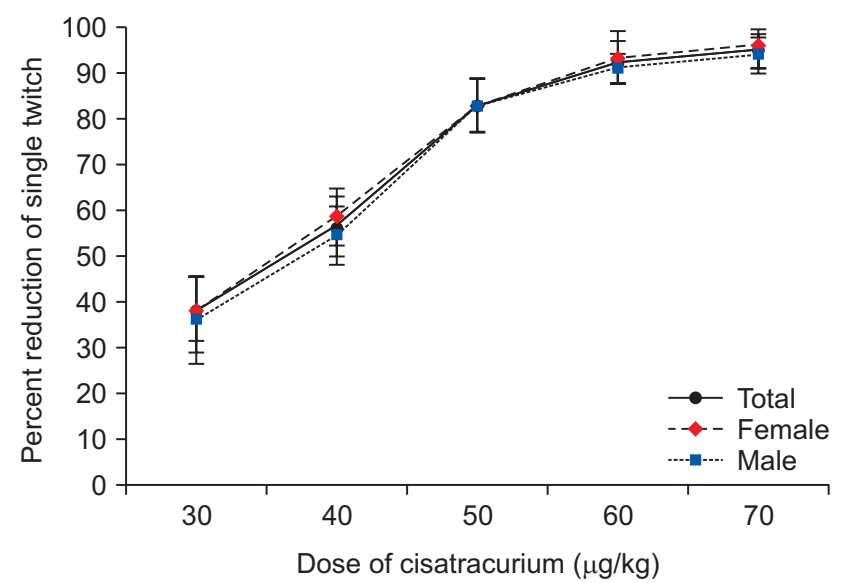

Fig. 2. This figure shows dose-response curve of cisatracurium in male, female and both gender. This dose-response relationship of cisatracurium was determined by single bolus method. Individual points represent $5 \%$, $25 \%, 50 \%, 75 \%, 95 \%$ reduction of single twitch response.

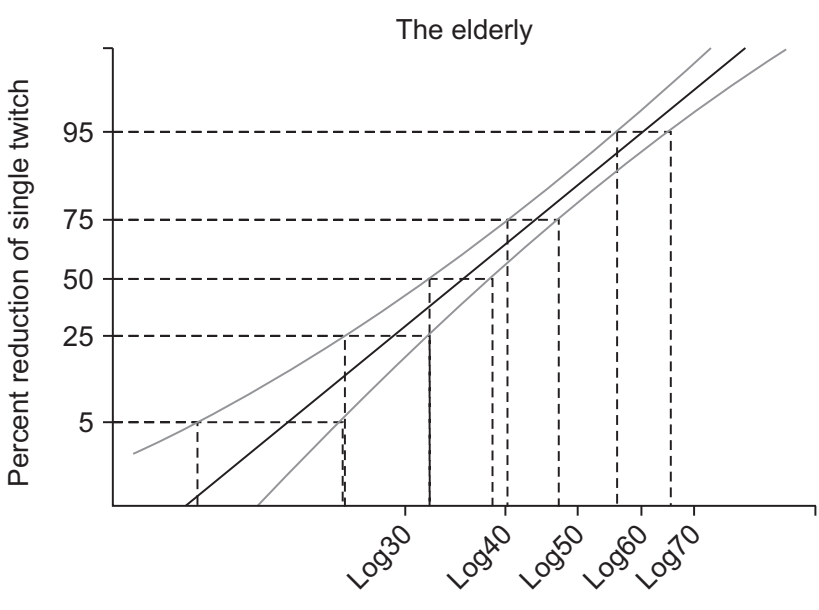

Log dose of cisatracurium $(\mu \mathrm{g} / \mathrm{kg})$

Fig. 1. These figures show dose-response linear regression of cisatracurium in the young and the adult. Linear regression analysis were constructed by SAS, version 9.3 (SAS institute Inc., NC, USA). Before regression analysis, each dose was transformed into logarithm and percent reduction of single twitch was transformed into probit. This transformation converts the sigmoid dose-response relationship of cisatracurium into the straight line. The probit values on ordinate represent $5 \%, 25 \%, 50 \%, 75 \%, 95 \%$ reduction of single twitch. 
of the dose depends on the organ, $16 \%$ of which is metabolized through the kidney. Studies on experimental animals found that cisatracurium was safer for the autonomic nervous system than were atracurium and vecuronium and that cisatracurium showed less secretion of histamine. No cardiovascular changes were observed with histamine secretion at 8 times the $\mathrm{ED}_{95}$ dose, and there was no increase in plasma histamine concentration when the doese was rapidly injected within 5 seconds. In addition, and similar to vecuronium, there was no change in the cardiovascular system with a double dose of $\mathrm{ED}_{95}$ administered to patients with coronary artery disease $[1,6]$.

Aging is a biological process that causes progressive changes in the structure and function of organs. The size and blood flow of the kidneys decrease with aging, which affects drug metabolism and fluid and electrolyte regulation; in addition, liver volume and blood flow decrease with aging as well. Although age does not generally affect the pharmacodynamics of muscle relaxants, if medication depends on hepatic or renal metabolism, the duration of action can be extended. However, the metabolism of cisatracurium by Hofmann elimination does not depend on organ function, and thus, any effect on the duration of action is not significantly increased in the elderly [7,8]. Sagir et al. [9] compared the effects of cisatracurium with those of rocuronium and vecuronium among elderly patients and reported that cisatracurium was suitable for the elderly because it acted quickly. Arain et al. [10] also showed that cisatracurium was appropriate for elderly patients because of its more rapid activation and low variability in the recovery index.

We estimated the effective dose of cisatracuirum by linear regression analysis; the $\mathrm{ED}_{95}$ for the adult group was $59.58 \mu \mathrm{g} /$ $\mathrm{kg}$, and that for the elderly group was $55.50 \mu \mathrm{g} / \mathrm{kg}$ (Table 3). The $P$ value was 0.562 following the homogeneity test between the estimated regression lines for the two groups, which indicated that the two lines were statistically homogeneous; furthermore, there was no significant difference in $\mathrm{ED}_{50}$ and $\mathrm{ED}_{95}$ between the adult and elderly groups (Fig. 1).

In the current study, the estimated $\mathrm{ED}_{50}$ and $\mathrm{ED}_{95}$ for the total patient group were $35.11 \mu \mathrm{g} / \mathrm{kg}$ (95\% CI 32.65, 37.16) and $57.31 \mu \mathrm{g} / \mathrm{kg}$ (95\% CI 54.40,60.19), respectively. The results of our study differed from the $48 \mu \mathrm{g} / \mathrm{kg}$ that was estimated as the $\mathrm{ED}_{95}$ of cisatracurium by Belmont et al. [11] and the $\mathrm{ED}_{50}$ and $\mathrm{ED}_{95}$ of, respectively, 30 and $53 \mu \mathrm{g} / \mathrm{kg}$ found by Lepage et al. [12]. Geographic location and race are known to influence the potency and duration of drug action. Dahaba et al. [13] found a significant difference in rocuronium potency and duration of action among patients in three countries; however, they also showed that there was no difference between Chinese and Caucasians in the comparative dose-response and time-course of cisatracurium activity [14]. The differences between the EDs in our study and those from existing studies [11,12] could be based on whether nitrous oxide was used. Nitrous oxide exhibits drugdrug interactions that strengthen the effects of neuromuscular blocking agents $[15,16]$; in particular, the two existing studies used nitrous oxide to maintain anesthesia compared with the propofol alone that we used to maintain anesthesia in this study.

Arain et al. [10] studied onset time, duration of action and recovery index time for rocuronium and cisatracurium among both adult and elderly patients, and they found that cisatracurium showed no significant difference between the two groups. In a study by Sorooshian et al. [17] the authors observed that a bolus dose of cisatracurium caused marginally greater neuromuscular block in young patients compared with elderly patients and that the block developed more slowly in the elderly; however, the duration of neuromuscular block was similar in both groups of patients. The authors of the study also compared the pharmacokinetics and pharmacodynamics of cisatracurium between adults and the elderly and reported a slight difference between the two groups. Kisor and Schmith [18] reported minor differences in the pharmacokinetics of cisatracurium besilate in various patient populations because of the unique relationship between plasma clearance and volume of distribution because the primary elimination pathway for cisatracurium besilate does not depend on organ function. In addition, a study by Ornstein et al. [19] showed only minor differences in the pharmacokinetics of cisatracurium between elderly and young patients; similar$l y$, the ED and the onset time in our study were not significantly different between the adult and elderly groups.

However, Joomye et al. [20] studied cisatracurium consumption and recovery index by age group $-20-45,46-64$ and $\geq 65$ years-and there were significant differences between the groups aged $20-45$ and $\geq 65$ years, likely because of the reduced body fluid that accompanies aging and that results in increased serum blood drug concentrations and increased volume of distribution due to increased body fat; the authors of that study suggested that the elderly require less cisatracurium to achieve a desirable effect. Although those authors reached their conclusion using consumption and recovery indexes with a closed-loop computer-controlled infusion, we investigated the cisatracurium ED and onset time with a single bolus. Furthermore, we classified the patients in this study into two groups, $<65$ years and $\geq 65$ years. In a review by Cope and Hunter [7], the effects of physiological changes on the pharmacokinetics of neuromuscularblocking agents did not become clinically apparent in healthy individuals of at least age 75 . In our current study, the average age in the elderly group was 71.4; we consider it a limitation of our study that it was not possible to clearly distinguish age differences between the groups. The $\mathrm{ED}_{50}$ and $\mathrm{ED}_{95}$ for the adult group were, respectively, 35.39 and $59.58 \mu \mathrm{g} / \mathrm{kg}$, whereas the $\mathrm{ED}_{50}$ and $\mathrm{ED}_{95}$ for the elderly group were 34.89 and $55.50 \mu \mathrm{g} / \mathrm{kg}$, respectively; although there were no statistical differences, there 
were still numeric gaps between the two groups. Thus, the topic warrants additional studies that are strictly designed with significantly more participants and distinct age differences between groups.

In addition, we estimated effective doses for men and women. For men, $\mathrm{ED}_{50}$ and $\mathrm{ED}_{95}$ were 35.79 (95\% CI 33.34, 37.89) and $64.50 \mu \mathrm{g} / \mathrm{kg}$ (95\% CI 61.07, 68.41), respectively, and those for women were 34.47 (95\% CI 30.74, 37.46) and $51.13 \mu \mathrm{g} / \mathrm{kg}$ (95\% CI 47.63, 54.85), respectively. The homogeneity test of the estimated regression line showed a $\mathrm{P}$ value $<0.05$, which means that the two regression lines were not homogenous and the $\mathrm{ED}_{95}$ confidence intervals did not match. In a study by Xue et al. [21], women were $30 \%$ more sensitive to rocuronium than were men. Additionally, Shi and Liang [22] found a significant difference in the effective dose of cisatracurium between men and women, with $\mathrm{ED}_{95}$ of $67.4 \pm 4.4$ and $48.7 \pm 1.0 \mu \mathrm{g} / \mathrm{kg}$, respectively. Although men showed higher proportions of body fluid and blood plasma, the distribution volume was expectedly lower in women; furthermore, men generally have more muscle mass and less fat, and hence women are expected to be more sensitive to muscle relaxants. A study by Adamus et al. [23] showed that the onset time and clinical duration of rocuronium were shorter in women than men, whereas those of cisatracurium did not differ between the two groups.
The times taken to reach maximum muscle relaxation were $375.4 \pm 76.9$ seconds and $369.1 \pm 70.0$ seconds in the adult group and elderly groups, respectively, with no statistically significant difference, and the results by dose also showed no statistically significant difference (Table 4). Lepage et al. [12] reported cisatracurium onset times of 6.7 (1.8, 9.3), 5.8 (3.3, 6.3), 6.7 (2.8, $12.5)$ and $7.7(5.5,8.5)$ minutes for $25,30,40$ and $60 \mu \mathrm{g} / \mathrm{kg}$, respectively, without statistical significance.

In summary, in this study, the $\mathrm{ED}_{50}$ and $\mathrm{ED}_{95}$ for cisatracurium in Korean adults and elderly persons were 35.11 (95\% CI $32.65,37.16)$ and $57.31 \mu \mathrm{g} / \mathrm{kg}(95 \%$ CI 54.40, 60.19), respectively. The ED and the onset time were not statistically different between the two groups, but a significant difference was observed between men and women in $\mathrm{ED}_{95}$ only.

\section{Acknowledgments}

This study was supported by research funds from Dong-A University.

\section{ORCID}

Jeong Ho Kim, http://orcid.org/0000-0003-4447-2838

Seung Cheol Lee, http://orcid.org/0000-0001-8669-5517

\section{References}

1. Naguib M, Lien CA, Meistelman C. Pharmacology of muscle relaxants and their antagonists. In: Miller's Anesthesia. 8th ed. Edited by Miller RD: Philadelphia, Churchill Livingstone/Elsevier. 2015, pp 958-94.

2. 2013 Statistics for the elderly [Internet]. Daejeon (KR): Statistics Korea. 2013 [cited 2016 Jan 20]. Available from http://kostat.go.kr/portal/ korea/kor_nw/2/6/1/index.board?bmode=read\&aSeq=308688.

3. Sieber F, Pauldine R. Geriatric anesthesia. In: Miller's Anesthesia. 8th ed. Edited by Miller RD: Philadelphia, Churchill Livingstone/Elsevier. 2015, pp 2407-22.

4. Vuyk J. Pharmacodynamics in the elderly. Best Pract Res Clin Anaesthesiol 2003; 17: 207-18.

5. Maybauer DM, Geldner G, Blobner M, Pühringer F, Hofmockel R, Rex C, et al. Incidence and duration of residual paralysis at the end of surgery after multiple administrations of cisatracurium and rocuronium. Anaesthesia 2007; 62: 12-7.

6. Kisor DF, Schmith VD. Clinical pharmacokinetics of cisatracurium besilate. Clin Pharmacokinet 1999; 36: 27-40.

7. Cope TM, Hunter JM. Selecting neuromuscular-blocking drugs for elderly patients. Drugs Aging 2003; 20: 125-40.

8. Slavov V, Khalil M, Merle JC, Agostini MM, Ruggier R, Duvaldestin P. Comparison of duration of neuromuscular blocking effect of atracurium and vecuronium in young and elderly patients. Br J Anaesth 1995; 74: 709-11.

9. Sagir O, Yucesoy Noyan F, Koroglu A, Cicek M, Ilksen Toprak H. Comparison between the effects of rocuronium, vecuronium, and cisatracurium using train-of-four and clinical tests in elderly patients. Anesth Pain Med 2013; 2: 142-8.

10. Arain SR, Kern S, Ficke DJ, Ebert TJ. Variability of duration of action of neuromuscular-blocking drugs in elderly patients. Acta Anaesthesiol Scand 2005; 49: 312-5.

11. Belmont MR, Lien CA, Quessy S, Abou-Donia MM, Abalos A, Eppich L, et al. The clinical neuromuscular pharmacology of 51 W89 in patients receiving nitrous oxide/opioid/barbiturate anesthesia. Anesthesiology 1995; 82: 1139-45.

12. Lepage JY, Malinovsky JM, Malinge M, Lechevalier T, Dupuch C, Cozian A, et al. Pharmacodynamic dose-response and safety study of cisatracurium (51W89) in adult surgical patients during N2O-O2-opioid anesthesia. Anesth Analg 1996; 83: 823-9.

13. Dahaba AA, Perelman SI, Moskowitz DM, Bennett HL, Shander A, Xiao Z, et al. Geographic regional differences in rocuronium bromide dose-response relation and time course of action: an overlooked factor in determining recommended dosage. Anesthesiology 2006; 104: 950-3. 
14. Dahaba AA, Suljevic I, Bornemann H, Wu XM, Metzler H. No regional difference in cisatracurium dose-response and time-course-ofaction between patients in China and Bosnia. Br J Anaesth 2011; 106: 331-5.

15. Kopman AF, Chin WA, Moe J, Malik R. The effect of nitrous oxide on the dose-response relationship of rocuronium. Anesth Analg 2005; 100: 1343-7.

16. Fiset P, Balendran P, Bevan DR, Donati F. Nitrous oxide potentiates vecuronium neuromuscular blockade in humans. Can J Anaesth 1991; 38: 866-9.

17. Sorooshian SS, Stafford MA, Eastwood NB, Boyd AH, Hull CJ, Wright PM. Pharmacokinetics and pharmacodynamics of cisatracurium in young and elderly adult patients. Anesthesiology 1996; 84: 1083-91.

18. Kisor DF, Schmith VD. Clinical pharmacokinetics of cisatracurium besilate. Clin Pharmacokinet 1999; 36: 27-40.

19. Ornstein E, Lien CA, Matteo RS, Ostapkovich ND, Diaz J, Wolf KB. Pharmacodynamics and pharmacokinetics of cisatracurium in geriatric surgical patients. Anesthesiology 1996; 84: 520-5.

20. Joomye S, Yan D, Wang H, Zhou G, Wang G. Consumption of Cisatracurium in different age groups, using a closed loop computer controlled system. BMC Anesthesiol 2014; 14: 29.

21. Xue FS, Tong SY, Liao X, Liu JH, An G, Luo LK. Dose-response and time course of effect of rocuronium in male and female anesthetized patients. Anesth Analg 1997; 85: 667-71.

22. Shi HJ, Liang QB. Impact of gender on the dose-effect relationship of cisatracurium. Nan Fang Yi Ke Da Xue Xue Bao 2011; 31: 1287-9.

23. Adamus M, Gabrhelik T, Marek O. Influence of gender on the course of neuromuscular block following a single bolus dose of cisatracurium or rocuronium. Eur J Anaesthesiol 2008; 25: 589-95. 